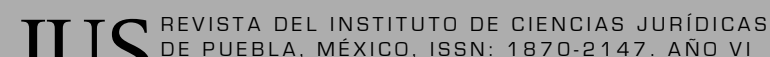

$1 \bigcup \begin{aligned} & \text { DE PUEBLA, MÉXICO, ISSN: } 1870-2147 \text {. AÑO VI } \\ & \text { NO. 29, ENERO-JUNIO DE } 2012 \text {, PP. 7-29 }\end{aligned}$

\title{
Fundamentos constitucionales de la protección jurídica de los consumidores en el ordenamiento español y en la Unión Europea*

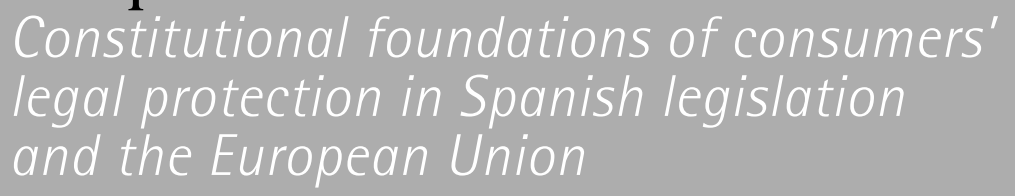

\section{Ángel Acedo Penco**}

\section{RESUMEN}

El presente artículo es una aproximación a las bases del reconocimiento constitucional de la protección juridica de los consumidores y usuarios en el sistema español, determinando los principios esenciales y caracteres que la presiden, incluyendo una sucinta exposición del ulterior desarrollo legislativo de aquel reconocimiento y sus referentes en el derecho de la Unión Europea que viene uniformando de manera muy enérgica el denominado derecho de consumo en los veintisiete países que en la actualidad conforman la agrupación comunitaria.

PALABRAS CLAVE: Derecho de consumo, protección de los consumidores, derechos constitucionales, España, Unión Europea.

\section{ABSTRACT}

This article is an approach to constitutional recognition of the legal protection of consumers and users in the Spanish system, determining the basic principles and characters, including a brief statement of the further legislative development of that recognition and their references in the European Union law.

KEY WORDS: Consumer law, consumers' protection, constitutional rights, Spain, European Union.

* Recibido: 3 de enero de 2012. Aceptado: 27 de enero de 2012.

** Profesor de Derecho civil en la Facultad de Derecho de la Universidad de Extremadura, Cáceres, España. (aacedo@unex.es). 


\section{Sumario}

1. Negación doctrinal de la protección jurídica del consumidor como categoría independiente

2. Fundamento constitucional de la protección de los consumidores en España
A) El artículo 51 de la Constitución española
B) El principio constitucional pro consumatore
c) Otros preceptos de refuerzo constitucional
D) Valoración crítica

3. Consecuencias legales del precepto constitucional

A) Legislación española anterior a 1984

B) Normativa española vigente entre 1984 y 2007

c) Legislación española actual

D) Ámbito territorial de aplicación

4. Competencias constitucionales del Estado español en materia de protección jurídica de los consumidores y usuarios

5. La legislación autonómica -regional- de consumo

6. El derecho de consumo comunitario europeo

A) El derecho constitucional u originario

B) El denominado derecho derivado

7. Rasgos esenciales del derecho de consumo español y europeo
A) Un derecho multidisciplinar
B) Dispone de diversas fuentes normativas
c) Carácter imperativo de sus normas
D) Cualidad tuitiva de sus preceptos
E) Protección optativa, compatible y complementaria
F) Otros caracteres básicos

8. La ıcu: norma esencial de derecho de consumo en España
A) Estructura formal
B) Contenido del Texto Refundido
c) Breve valoración crítica

8

\section{Negación doctrinal de la protección jurídica del consumidor como categoría independiente}

Quizá, sin toda la razón, la inmensa mayoría de la doctrina española actual viene negando, con rotundidad, la existencia de una disciplina jurídica nueva e independiente, desgajada del derecho civil o mercantil, denominada "derecho de consumo", "derecho del consumidor" o "derecho de los consumidores", en defi- 
nitiva, de un cuerpo normativo especial, con sus propios principios, sistemática e instituciones, diferentes a los de las demás ramas del derecho ya consolidadas. ${ }^{1}$

Por otro lado, destacados autores alemanes defienden la necesidad de tutelar al consumidor más allá que al resto de los sujetos, dada su posición marcadamente débil en los contratos de consumo, respecto del profesional oferente, al modo de la protección que concede el derecho laboral a los trabajadores frente a los empresarios.

Además, también se sostiene la idea de un derecho de consumo, no ya como categoría dogmática independiente, sino meramente funcional, y que se define como aquel que tiene como finalidad la de "proporcionar a los consumidores y usuarios la protección que precisan, desde el punto de vista jurídico, la que aúna y da sentido propio a la categoría".

Se ha argumentado, a nuestro juicio, con pleno acierto, que existe en el ordenamiento jurídico español y europeo un principio general pro consumatore (a favor del consumidor), proclamado en el artículo 51 de la Constitución Española (en adelante $\mathrm{CE}$ ) que obliga a que la aplicación de toda la legislación vigente española haya de interpretarse, sin traba, en el sentido más favorable a los intereses de los consumidores, además del expreso reconocimiento de una obligación genérica de información de los profesionales o empresarios cuando contraten con consumidores.

Al margen de las discusiones doctrinales acerca de la cuestión, lo cierto es que ya se contempla el derecho de consumo como derecho especial, ya como una particular rama del derecho o como una simple categoría funcional, lo cierto y práctico es que no parece que sea condenable la tendencia de tratar conjuntamente todas las reglas que se refieran a la condición jurídica de las personas en una determinada situación social, como es el caso de los llamados consumidores y usuarios. ${ }^{3}$

Y aunque tampoco debemos desdeñar las ventajas que entraña el estudio de la normativa que afecta a los consumidores, dentro del sistema propio de las reglas de la misma naturaleza, conforme a las clasificaciones de las tradicionales ramas del derecho (civil, mercantil, administrativo y penal), quizá, a efectos no sólo didácticos, sino también prácticos, no sea ociosa una aproximación a esta

\footnotetext{
1 Respecto a la cuestión, puede verse con mayor amplitud, Acedo Penco, Ángel. Derecho de consumo. Análisis jurídicoprivado de la ley general para la defensa de los consumidores de 2007, Dykinson, Madrid, 2012.

2 Martinez de Aguirre y Aldaz, Carlos. "Comentario al artículo 7o. de la lgdcu", en Bercovitz, Rodrigo y Salas Javier (coords.). Comentarios a la Ley General para la Defensa de los Consumidores y Usuarios, Civitas, Madrid, 1992, p. 120.

3 De Castro y Bravo, Federico. "Notas sobre las limitaciones intrínsecas de la autonomía de la voluntad. La defensa de la competencia. El orden público. La protección del consumidor", en Anuario de Derecho Civil, t. Xxxv, fascículo IV, Ministerio de Justicia, Madrid, octubre-diciembre de 1982, pp. 1021 y ss., y 1075-1078.
} 
ÁNGEL ACEDO PENCO

materia desde un punto de vista conjunto, ratione materiae, tal como se viene haciendo en otros ordenamientos diferentes al español.

El Tribunal Constitucional español (en adelante Tc) pronto declaró que el

[...] artículo 51, cE, en sus apartados 1 y 3, en cuanto atribuye a los poderes públicos "la defensa de los consumidores y usuarios", prevé, a tal efecto, que "la Ley regulará el comercio interior y el régimen de autorización de los productos comerciales" -por tanto- la defensa del consumidor aparece así como un principio rector de la política social y económica, cuya garantía la Constitución impone a los poderes públicos. ${ }^{4}$

La elevación a rango constitucional de la protección de los consumidores y usuarios, como principio rector de la política social y económica, tal como indica el artículo 53.3 CE, y, en definitiva, al principio general de derecho, debe suponer, entre otras consecuencias, que en caso de conflicto entre diversas normas aplicables en las contiendas entre individuos particulares y productores o empresas, los jueces y tribunales deban decantarse en favor de la interpretación que otorgue una mayor defensa de los intereses de tales consumidores, mediante el llamado principio pro consumatore contenido en el artículo 51.1 CE.

\section{Fundamento constitucional de la protección de los consumidores en España}

\section{A) El artículo 51 de la Constitución española}

Los constituyentes (redactores de la Constitución española del 27 de diciembre de 1978) no fueron ajenos a la evolución de los movimientos sociales y las normas protectoras en materia de consumo que se venían desarrollando en toda Europa y, especialmente, en el ámbito de la entonces llamada Comunidad Económica Europea ( $\mathrm{CEE}$ ), además del reciente reconocimiento de la protección del consumidor en la Constitución de Portugal del 25 de abril de 1976.

Así, decidieron dedicar un artículo específico para reconocer la protección de los consumidores y usuarios, el artículo 51 cE, cuyo texto definitivo fue ultimado en la Cámara Alta por clara influencia del Programa Preliminar de la Comunidad Económica Europea, aprobado por la Resolución del Consejo Europeo del 14 de abril de 1975.

\footnotetext{
${ }^{4}$ Sentencia del Tribunal Constitucional del reino de España (SтC) No. 88/1986, del 1 de julio, fundamento jurídico 4.
} 
El artículo $51 \mathrm{cE}$, incluido entre los "Principios rectores de la política social y económica” regulado en el capítulo tercero, dentro del título ı, relativo a los derechos y deberes fundamentales, determina en el párrafo primero que: "los poderes públicos garantizarán la defensa de los consumidores y usuarios, protegiendo mediante procedimientos eficaces la seguridad, la salud y los legítimos intereses de los mismos".

Consciente de la importancia de los movimientos consumeristas europeos, y atendiendo las Directivas comunitarias que ya impulsaban su desarrollo, expresa el párrafo segundo del artículo 51 CE que: "los poderes públicos promoverán la información y la educación de los consumidores y usuarios, fomentarán sus organizaciones y oirán a éstas en las cuestiones que puedan afectar a aquéllos, en los términos que la ley establezca”.

Finaliza el decisivo precepto constitucional con un tercer párrafo que completa los dos anteriores, de manera específica, al indicar que: "en el marco de lo dispuesto por los apartados anteriores, la ley regulará el comercio interior y el régimen de autorización de productos comerciales".

\section{в) El principio constitucional pro consumatore}

El artículo 51 cE debe conectarse con el artículo 53.3 cE, que expresa que "el reconocimiento, el respeto y la protección de los principios reconocidos en el capítulo tercero, informará la legislación positiva, la práctica judicial y la actuación de los poderes públicos. Sólo podrán ser alegados ante la jurisdicción ordinaria de acuerdo con lo que dispongan las leyes que los desarrollen".

Ello constata el reconocimiento expreso en el derecho español, con rango constitucional, del "principio general de defensa y protección de los consumidores y usuarios", con las consecuencias que a ellos otorga tal precepto, lo que implica que este principio pro consumatore deberá tenerse siempre presente en: a) la elaboración de la legislación positiva; $b$ ) la práctica judicial, y c) la actuación de todos los poderes públicos.

El mismo artículo 53.1 cE establece, de una parte, que tales derechos vinculan a todos los poderes públicos, $\mathrm{y}$, de otra, contiene una reserva de ley en favor de del derecho a la protección de los consumidores y usuarios, es decir, que el desarrollo legislativo de su regulación se encomienda a una norma con rango de ley, que será el instrumento jurídico en el que habrán de basarse quienes soliciten el amparo de los jueces y tribunales en defensa de estos derechos y principios, como determina el artículo 53.3 cE. 
ÁNGEL ACEDO PENCO

Si bien el principio pro consumatore partió de una interpretación de la doctrina, según se ha expuesto, la aprobación de la nueva LCu en 2007 lo ha "legalizado" o, mejor dicho, "constitucionalizado" de manera expresa en el primero de sus artículos, al indicar que la propia tcu "en desarrollo del artículo 51.1 y 2 de la Constitución que, de acuerdo con el artículo 53.3 de la misma, tiene el carácter de principio informador del ordenamiento jurídico".

\section{c) Otros preceptos de refuerzo constitucional}

Además, según el artículo 54 cE, el Defensor del Pueblo también tendrá entre sus funciones la defensa de los consumidores y usuarios, aunque lo cierto es que, habida cuenta de la extensa y variada gama de derechos que a esta institución corresponde proteger, quizá su efectividad en este campo no sea la deseada. En este sentido, cabe recordar que en Suecia, por ejemplo, para solucionar dicho problema se ha creado específicamente la figura del ombudsman (defensor) de los consumidores, con lo que se garantiza una exclusiva dedicación a tan importante tarea.

Al margen de los citados, en otros preceptos constitucionales se aluden o reconocen expresamente ciertos derechos que tienen clara conexión con la protección de los consumidores, destacando especialmente el artículo $43 \mathrm{CE}$, donde se reconoce el derecho a la salud (con carácter universal), incluido y protegido también por el artículo 51.1, aunque sólo a los consumidores.

\section{D) Valoración crítica}

Desde nuestro punto de vista, la valoración de la inclusión de la protección constitucional otorgada por el artículo 51 CE a los consumidores en España es claramente positiva, pues constituye una acertada innovación en el panorama europeo que va mucho más allá que su antecesora, la Constitución de Portugal de 1976, ya pionera, aunque tímidamente, en esta materia en Europa.

Sin embargo, el artículo 51 cE también contiene algunas sombras, que si no existieran dotarían de mayor perfección al precepto, ya que se olvida de indicar algo tan decisivo como qué debe entenderse por consumidor, es decir, a qué sujetos protege, y también a qué materias se extiende aquella protección, máxime cuando de desarrollo legal de estos dos extremos resulta, a nuestro modo de ver, abiertamente insatisfactorio. 


\section{Consecuencias legales del precepto constitucional}

\section{A) Legislación española anterior a 1984}

Aunque en España no hubiera una ley concreta de protección de los consumidores y usuarios no significa que los intereses de aquéllos hubieran estado absolutamente desprotegidos jurídicamente, pues siempre existieron los mecanismos legales a disposición de todos los ciudadanos, en especial el Código Civil y también el Código de Comercio, vigentes desde la codificación, entre los que destacan los siguientes preceptos protectores de la parte más débil del contrato:

a) El artículo 1255 cc, decisivo, impone "la Ley, la moral y el orden público" como límites a la libertad de contratación, pues no todo vale aunque expresamente así figure en el contrato.

b) El artículo 1256 cc: "la validez y cumplimiento de los contratos no puede dejarse al arbitrio de una de las partes", evitando grandes injusticias.

c) La irrenunciabilidad de la acción para exigir la responsabilidad procedente del dolo, del artículo 1102 cc, protegiendo al engañado.

d) El principio contra stipulatorem sobre interpretación contractual, impidiendo favorecer a quien propicia la oscuridad, del artículo 1288 cc.

e) El artículo 59 del Código de Comercio indica que si no se resuelve la duda interpretativa del contrato "se dictará la cuestión a favor del deudor".

Además de los códigos, se promulgaron leyes intervencionistas, ya específicamente protectoras de los consumidores, contenidas en normas destinadas a regular diferentes sectores de la actividad socioeconómica española, como el transporte aéreo, defensa de la competencia, la publicidad comercial, la venta a plazos de bienes muebles y la de viviendas en construcción, el contrato de seguro y alguna otra de carácter sancionador. ${ }^{5}$

\section{в) Normativa española vigente entre 1984 y 2007}

Cumpliendo, tardíamente, el obligado desarrollo legislativo básico de dicho precepto constitucional, se promulgó la Ley 26/1984, del 19 de julio, General para

\footnotetext{
5 a) Ley de la Navegación Aérea, del 21 de julio de 1960, aún vigente; b) Ley de Prácticas Restrictivas de la Competencia del 20 de julio de 1963, hoy derogada; c) Estatuto de la Publicidad del 11 de junio de 1964, derogado; d) Ley de Ventas de Bienes Muebles a Plazos, del 7 de julio de 1965, también derogada; e) Ley sobre Percepciones de Cantidades Anticipadas en la Construcción de Viviendas, del 17 de julio de 1968, vigente; f) Ley de Contrato de Seguro, del 8 de octubre de 1980 (LCS), vigente, y g) Real Decreto 1945/1983, del 22 de junio, por el que se regulan las infracciones y sanciones en materia de defensa del consumidor y de la producción agroalimentaria, también vigente en la actualidad.
} 
la Defensa de los Consumidores y Usuarios, que estableció un catálogo de derechos mínimos, un régimen de garantías y responsabilidades para proteger al consumidor.

El carácter general de aquella ley, que ha estado vigente durante más de dos décadas, precisaba de una prolija y extensa reglamentación sectorial mediante diferentes cuerpos normativos, en función de la materia y contenidos que se regulen, cuya correcta aplicación por medio de los diferentes operadores jurídicos debía garantizar una adecuada protección de los derechos e intereses de los consumidores.

La posterior ley 44/2006, del 29 de diciembre, de mejora de la protección de los consumidores y usuarios, incluyó en su disposición final quinta una habilitación al gobierno para refundir en un único texto la Ley General de Defensa de los Consumidores y Usuarios, del 19 de julio de 1984, y las normas de transposición de las Directivas sobre protección de los consumidores que inciden en los aspectos regulados en ella, regularizando, aclarando y armonizando los textos legales afectados.

\section{c) Legislación española actual}

Fruto de aquel mandato legal se promulgó el Real Decreto Legislativo 1/2007, del 16 de noviembre, por el que se aprueba el texto refundido de la Ley General para la Defensa de los Consumidores y Usuarios y otras leyes complementarias (en adelante $\mathrm{LCu}$ ), que deroga la Ley de 1984, también otras cuatro leyes completas sobre contratos fuera de los establecimientos comerciales, responsabilidad civil del fabricante, viajes combinados y garantía en la venta de bienes de consumo. ${ }^{6}$

Sin embargo, pese a estas derogaciones, el contenido de las leyes, que se dejan sin efecto, se transcribe de manera casi íntegra, con mejor técnica, en el nuevo texto refundido del Real Decreto Legislativo 1/2007.

La entrada en vigor de las leyes específicas de protección al consumidor no agota, con mucho, el desarrollo legislativo del mandato constitucional, sino que se han promulgado un nutrido grupo de leyes y otras normas estatales respecto a las diferentes materias y sectores específicos referidos a la protección de los dere-

\footnotetext{
${ }^{6}$ En particular, la nueva Lcu deroga las siguientes normas: a) Ley 26/1984, del 19 de julio, General para la Defensa de los Consumidores y Usuarios; b) La Ley 26/1991, del 21 de noviembre, sobre contratos celebrados fuera de los establecimientos mercantiles; c) Ley 22/1994, del 6 de julio, de responsabilidad civil por los daños causados por productos defectuosos; d) Ley 21/1995, del 6 de julio, reguladora de los viajes combinados; e) Ley 23/2003, del 10 de julio, de garantías en la venta de bienes de consumo; f) Escasos preceptos de la Ley 7/1996, del 15 de enero, de ordenación del comercio minorista: artículos 48 y 65.1 -de éste sólo sus letras $n$ y ñ-, así como la disposición adicional primera.
} 
chos e intereses de los consumidores y usuarios, todo ello, además, al margen de la normativa autonómica de consumo, en no pocas veces repetitiva de la estatal.

En definitiva, como ha puesto de relieve la doctrina, la Lcu "no lleva a cabo una reconstrucción "mecánica" de los textos, sino que introduce bastantes novedades, no pocas de ellas de notable relevancia práctica"?

Téngase en cuenta que el artículo 82.3 cE dispone que "la autorización para refundir textos legales determinará el ámbito normativo a que se refiere el contenido de la delegación, especificando si se circunscribe a la mera formulación de un texto único o si se incluye la de regularizar, aclarar y armonizar los textos legales que han de ser refundidos". La ucu es claro que no se limita a aquella mera formulación legal, sino que regulariza, aclara y armoniza, e incluso complementa, generosamente, los textos refundidos.

\section{D) Ámbito territorial de aplicación}

El artículo 139.1 CE establece la igualdad en la aplicación de las leyes para todos los ciudadanos independientemente del lugar donde se encuentren, al indicar que: "Todos los españoles tienen los mismos derechos y obligaciones en cualquier territorio del Estado", principio matizado en función de las diferentes legislaciones autonómicas que permiten regulaciones distintas para las materias que sean de competencia de las CCAA.

La lcu tiene carácter general, de aplicación básica en todo el Estado español, pues la mayoría de las materias reguladas son de competencia exclusiva del Estado, lo que significa que esta ley fija un contenido mínimo en materia de derecho de consumo ampliable por las CCAA.

La citada STC 15/1989, del 26 de enero, expresó que aunque la ley de Consumidores de 1984 no era de aplicación directa a aquellas Comunidades Autónomas que habian asumido constitucionalmente competencia plena sobre la defensa de los consumidores y usuarios en virtud de sus respectivos Estatutos de Autonomía, sin embargo, al tener carácter "general”, la legislación de consumo (también la LCu de 2007) será de aplicación en todo el territorio nacional, es decir, que las Comunidades Autónomas deben "acatar su contenido mínimo", cuyos derechos reconocidos deben ser comunes en todo el territorio español, si bien aquéllas pueden legislar desarrollando las instituciones sobre defensa de los consumidores que le permitan sus propios estatutos autonómicos. ${ }^{8}$

\footnotetext{
7 Cavanillas Múgica, Santiago. "El Real Decreto Legislativo 1/2007 por el que se aprueba el texto refundido de la Ley General para la Defensa de los Consumidores y Usuarios y otras leyes complementarias", en Aranzadi Civil, No. 1, 2008, pp. 2133-2166.

${ }^{8}$ La stc 15/1989 declaró que los artículos 1.1, 6, 7, 13.2, último inciso, 14-19, 22, puntos 1-4, y 6, 23, 36.2, 39.5
} 
Atendiendo a lo dispuesto en la doctrina del Tribunal Constitucional que se ha citado, la redacción del vigente artículo 1 Lcu, bajo la rúbrica de "Principios generales", determina que:

[...] en desarrollo del artículo 51.1 y 2 de la Constitución que, de acuerdo con el artículo 53.3 de la misma, tiene el carácter de principio informador del ordenamiento jurídico, esta norma tiene por objeto establecer el régimen jurídico de protección de los consumidores y usuarios en el ámbito de las competencias del Estado.

Además, dicho precepto añade, respecto de su ámbito de aplicación: "En todo caso, la defensa de los consumidores y usuarios se hará en el marco del sistema económico diseñado en los artículos 38 y 128 de la Constitución y con sujeción a lo establecido en el artículo 139".

\section{Competencias constitucionales del Estado español en materia de protección jurídica de los consumidores y usuarios}

Entre la distribución de competencias exclusivas atribuidas al Estado por el artículo 149.1 cE no se encuentra la protección de los consumidores, como tampoco se atribuye expresamente, en el artículo 148, a las Comunidades Autónomas la posibilidad de asumirla en esta materia. Lo anterior determina, según el artículo 149.3 CE, una cláusula residual en favor del Estado, en el sentido de atribuirle todas las competencias que no se detallan en el artículo $148 \mathrm{cE}$, o que, estando citadas, no han sido expresamente asumidas por los Estatutos de Autonomía por parte de las Comunidades Autónomas.

En principio, corresponde al Estado la competencia en materia de protección de los consumidores y usuarios, materia que tiene carácter multidisciplinar, pues afecta a diversas competencias, salvo que los Estatutos hayan asumido expresamente dicha competencia con carácter exclusivo, en cuyo caso habrán de respetar, naturalmente, las demás competencias estatales ya atribuidas por otros títulos competenciales. En todo caso, al no contenerse expresamente la defensa de los consumidores y usuarios en ninguno de los catálogos de competencias recogidos en los artículos 148.1 (competencias de las Comunidades Autónomas) y 149.1 CE (competencias del Estado), y pese a haberse asumido de manera ple-

y 41 de la Ley de 1984 no eran de aplicación directa en las Comunidades Autónomas que constitucionalmente, en virtud de sus respectivos Estatutos de Autonomía, habian asumido la competencia plena sobre defensa de los consumidores y usuarios. En la misma resolución determina que tampoco el artículo 20.1 y 2 era de aplicación directa en las Comunidades que, estatutariamente, hubieran adoptado la competencia sobre asociaciones de consumidores y usuarios. 
na, o menos plena, por parte de las Comunidades Autónomas, lo cierto es que muchos de los contenidos que afectan a esta materia sí que han sido atribuidos de manera exclusiva al Estado, por lo que se produce un choque competencial que habrá que resolver en favor de éste o aquéllas.

Una gran parte del derecho civil, en particular la regulación del "régimen de los contratos", es competencia exclusiva del Estado, al otorgarse a éste, de manera expresa, las bases de "las obligaciones contractuales", en el artículo 149.1.8 $\mathrm{CE}$, y también el derecho mercantil, al atribuirle también la "legislación mercantil” en el artículo 149.1.6 CE, por lo que, incluso las Comunidades Autónomas que han asumido con carácter exclusivo, y de manera plena, la competencia en materia de consumo, aunque sean aquellas que gocen también de la competencia para "desarrollar, conservar y modificar su propio derecho civil", deberán respetar la regulación del Estado referida al derecho de consumo, pues gran parte del contenido de éste lo conforman normas de derecho mercantil y las bases de las obligaciones contractuales.

La Sentencia del Tribunal Constitucional (sтc) del 22 de marzo de 1991 declaró la inconstitucionalidad de las normas de consumo las Comunidades Autónomas con competencia en materia de desarrollo de su derecho civil (en concreto en Galicia), al suponer una regulación del contenido de los contratos distinta de la normativa establecida con carácter estatal.

Otros pronunciamientos del mismo tribunal, como la importante sTc del 3 de noviembre 1982, han declarado también que resultan inconstitucionales determinados preceptos de la legislación vasca de consumo al modificar el régimen de responsabilidad civil que debe ser igual para todo el territorio español.

En materia de derecho de la competencia, la STc 264/1993, del 22 de julio, declaró la inconstitucionalidad de varios preceptos autonómicos (Ley aragonesa de ordenación de la actividad comercial) por invadir materias de titularidad estatal.

Los horarios comerciales han sido considerados de competencia estatal, declarando la STC (Pleno) 225/1993, del 8 de julio, la inconstitucionalidad de la normativa autonómica (ley valenciana sobre ordenación del comercio y superficies comerciales) que no respetaba los límites fijados por la legislación estatal. Posteriormente, el mismo día, se aprobó la Ley 7/1996, del 15 de enero, de Ordenación del Comercio Minorista (LCM) y la Ley Orgánica 2/1996, del 15 de enero (Locm), complementaria de la anterior, que encomiendan a las Comunidades Autónomas la regulación sobre los horarios del comercio, pero respetando, en todo caso, los mínimos que hayan sido fijados por la ley estatal.

En definitiva, a la vista de prevalencia de las normas estatales sobre regulación de los contratos, así como de la responsabilidad civil y, en todo caso, 
ÁNGEL ACEDO PENCO

la referente a la legislación mercantil, ambas de enorme proyección dentro del derecho de consumo -y la doctrina consolidada del Tribunal Constitucional que impide a las Comunidades Autónomas reproducir la regulación estatal en materia de defensa de los consumidores referidas a materias competencia exclusiva del Estado-, parece evidente que el margen de regulación autonómica es más bien limitado, incluso, como se ha puesto de manifiesto por la doctrina, cuando aquélla pretenda otorgar un nivel de protección superior al contenido en la norma estatal, aunque, en última instancia, corresponderá a dicho tribunal resolver este último aspecto a la vista del principio contenido en el artículo 51 cE.

Pueden resumirse, de forma básica y elemental, las competencias de consumo, según los artículos 149 y $139.2 \mathrm{cE}$, y la doctrina constitucional de las ya citadas SSTc 71/1982 y 88/1986, por lo que, con carácter exclusivo, corresponde al Estado el ejercicio de las siguientes competencias:

a) Legislación civil, salvo el derecho foral.

b) El aseguramiento de la unidad de mercado.

c) La legislación mercantil.

d) Las bases de las obligaciones contractuales.

e) La responsabilidad civil derivada de las relaciones contractuales.

f) La responsabilidad civil extracontractual.

g) Las condiciones generales de la contratación.

h) El derecho penal y procesal.

Finalmente, la Sentencia del Pleno del Tribunal Constitucional 31/2010, del 28 de junio de 2010 (sobre el Estatuto de Cataluña), sintetiza en su Fu 70 que:

[...] la materia de defensa de los consumidores es un ámbito de concurrencia competencial de títulos habilitantes diferentes, de manera que la atribución estatutaria de la competencia de carácter exclusivo a la Comunidad Autónoma no puede afectar a las competencias reservadas por la Constitución al Estado (artículo 149.1, CE), que se proyectarán cuando materialmente corresponda (STC 15/1989, del 26 de enero, FJ 1).

\section{La legislación autonómica -regional- de consumo}

La "protección de los consumidores y usuarios" no se encuentra prevista, en la Constitución, entre las competencias específicas del Estado, ni tampoco de las Comunidades Autónomas, sin perjuicio de lo expuesto respecto de ciertas materias sobre consumo, que son de competencia exclusiva estatal. 
No obstante, tal vez debido a la creciente importancia que en nuestra sociedad ha ido adquiriendo la protección de los consumidores, lo cierto es que, hasta la fecha, la casi totalidad de las Comunidades Autónomas que conforman el territorio español (que son diecisiete, en las que se estructura el reino de España), excepto La Rioja, han promulgado, cada una de ellas, sus propias leyes autonómicas específicas de consumo o sus estatutos legales de defensa del consumidor, con rango formal de ley autonómica. ${ }^{9}$

\section{El derecho de consumo comunitario europeo}

\section{A) El derecho constitucional u originario}

También denominado "derecho constitucional de la Unión Europea", el derecho originario tiene su base en el Tratado Roma del 25 de marzo de 1957, constitutivo de la Comunidad Económica Europea (CEE) ${ }^{10}$ no alude de manera directa a los consumidores, ni establece medidas de protección específicas para este sector, aunque sí que contiene algunas referencias indirectas a lo largo de todo el tratado, referentes a la mejora constante de las condiciones de vida como finalidad

\footnotetext{
${ }^{9}$ En España, al término de la redacción de estas líneas, están vigentes las siguientes leyes autonómicas de protección del consumidor: Ley 13/2003, del 17 de diciembre, de Defensa y Protección de los Consumidores y Usuarios de Andalucia (Boletín Oficial del Estado, en adelante BoE, No. 14, del 16 de enero de 2004); Ley 16/2006, del 28 de diciembre, de Protección y Defensa de los Consumidores y Usuarios de Aragón (BOE No. 45, del 21 de febrero de 2007); Ley 3/2003, del 12 de febrero, del Estatuto de los Consumidores y Usuarios de la Comunidad Autónoma de Canarias (BOE No. 56, del 6 de marzo de 2003); Ley 1/2006, del 7 de marzo, de Defensa de los Consumidores y Usuarios de Cantabria (boe No. 77, del 31 de marzo de 2006); Ley 11/2005, del 15 de diciembre, del Estatuto del Consumidor de Castilla-La Mancha (BOE No. 255, del 20 de diciembre de 2005); Ley 11/1998, del 5 de diciembre, de Defensa de los Consumidores y Usuarios de Castilla y León (BOE No. 16, del 19 de enero de 1999); Ley 22/2010, del 20 de julio, del Código de Consumo de Cataluña (BOE No. 196, del 13 de agosto de 2010); Ley 2/1987, del 9 de abril, del Estatuto de Consumidores y Usuarios de la Comunidad Valenciana (BOE No. 102, del 29 de abril de 1987); 6/2001, del 24 de mayo, del Estatuto de los Consumidores de Extremadura (BOE No. 173, del 20 julio 2001); Ley 12/1984, del 28 de diciembre, del Estatuto del Consumidor y Usuario de la Comunidad de Galicia (BOE No. 139, del 11 de junio de 1985); Ley 1/1998, del 10 de marzo, del Estatuto de los Consumidores y Usuarios de la Comunidad Autónoma de las Islas Baleares (BOE No. 113, del 12 de mayo de 1998); Ley 11/1998, del 9 de julio, de Protección de los Consumidores y Usuarios de la Comunidad de Madrid (BOE No. 206, del 28 de agosto de 1998); Ley 7/2006, del 20 de junio, de Defensa de los Consumidores y Usuarios de Navarra; Ley 6/2003, del 22 de diciembre, de Estatuto de las Personas Consumidoras y Usuarias del Pais Vasco (Bopv No. 254, del 30 de diciembre de 2003); Ley 11/2002, del 2 de diciembre, de los Consumidores y Usuarios, del Principado de Asturias (BOE No. 13, del 15 de enero de 2003); Ley 4/1996, del 14 de junio, del Estatuto de los Consumidores y Usuarios de la Región de Murcia (BOE No. 238, del 2 de octubre de 1996). Todas ellas pueden consultarse en el sitio oficial de Internet - de acceso libre y universal- del Boletín Oficial del Estado español: www.boe.es.

10 Se conoce como derecho originario comunitario europeo, y también, derecho constitucional comunitario, aquel que procede directamente de los tratados internacionales constitutivos de la Unión Europea (antes Comunidad Económica Europea) y sus posteriores reformas.
} 
primordial de la entonces ceE, según indicaba el artículo 3 de su Preámbulo, así como la "rápida elevación del nivel de vida de sus ciudadanos", tal como establece el artículo 2 .

No fue hasta la Conferencia de Jefes de Estado de París, celebrada el 19 y 20 de octubre de 1972 (Cumbre de París), cuando se comenzó a ejecutar una política ordenada en materia de consumo, solicitándose allí que los órganos comunitarios elaboraran un programa específico para robustecer y coordinar medidas de protección al consumidor, al preocuparse los Estados miembros por dar "un aspecto humano" a la Comunidad Europea, lo que habría de traducirse en una mejora de la calidad de vida de los europeos.

La elaboración de la Carta de Protección del Consumidor, el 17 de mayo de 1973, por parte de la Asamblea Consultiva del Consejo de Europa, supuso el inicio de la política comunitaria de protección del consumidor.

La aprobación del Acta Única Europea, ${ }^{11}$ que reformó el Tratado de Roma en materia de mercado interior, supuso, por primera vez, la protección expresa de los consumidores en la Europa comunitaria, extremo de gran importancia, pues nunca antes había aparecido esta mención en un tratado constitutivo comunitario, y aunque esta mención no establece todavía ninguna política concreta de protección al consumidor, incluye entre sus objetivos "la protección de la salud de las personas", "asegurar al consumidor suministros a precios razonables" y "limitar la producción, el mercado o el desarrollo técnico en perjuicio de los consumidores".

El Tratado de Maastricht ${ }^{12}$ se propone la "contribución al fortalecimiento de la protección de los consumidores, ${ }^{13}$ y que "la Comunidad contribuirá a que se alcance un alto nivel de protección de los consumidores a fin de proteger la salud, la seguridad y los intereses económicos de los consumidores y garantizarles una información adecuada". ${ }^{4}$

Tras la reforma del Tratado de Roma, constitutivo de la ceE, llevada a cabo mediante el Tratado de Ámsterdam, ${ }^{15}$ el nuevo artículo 153.1, vigente en la actualidad, determina que: "la Comunidad contribuirá a proteger la salud, la seguridad

\footnotetext{
11 Firmada el 17 (en Luxemburgo) y el 28 (en La Haya) de febrero de 1986, que entró en vigor el 1 de julio de 1987, ratificada por España por Instrumento del 9 de diciembre de 1986 (mediante la Ley Orgánica 4/1986, del 26 de noviembre).

12 Firmado el 7 de febrero de 1992, que entró en vigor el 1 de noviembre de 1993, ratificado por España en Instrumento del 29 de diciembre de 1992.

13 Artículo 6.S).

14 Artículo 129.A.

15 Firmado el 2 de octubre de 1997, ratificación autorizada en España mediante la Ley Orgánica 9/1998, del 16 de diciembre.
} 
y los intereses económicos de los consumidores, así como a promover su derecho a la información, a la educación y a organizarse para salvaguardar sus intereses”. ${ }^{16}$

\section{B) El denominado derecho derivado}

En el plano del derecho derivado, ${ }^{17}$ en 1973 se crea el Servicio de Medio Ambiente y de Protección de los Consumidores europeo a cargo de un comisario, y se constituye el Comité Consultivo de los Consumidores para representar, ante la propia Comisión, los intereses de los consumidores y las políticas de consumo, ${ }^{18}$ aprobándose diversos y decisivos Planes de actuación. ${ }^{19}$

Los primeros frutos de esta política fueron la aprobación de las primeras Directivas Comunitarias para la protección de los consumidores, destacando la Directiva 84/450/CEE sobre publicidad engañosa; Directiva 85/374/CEE sobre responsabilidad del fabricante por daños de productos defectuosos; Directiva 85/577/CEE de contratos negociados fuera de los establecimientos comerciales, y Directiva 87/102/ceE reguladora del crédito al consumo.

Sin carácter vinculante, pero de una influencia decisiva, se adoptaron posteriormente: la Recomendación 87/598/CEE que aprobó el Código europeo de buena conducta en materia de pago electrónico, y la Recomendación 88/59/ CEE sobre sistema de pago y relaciones entre titulares y emisores de tarjetas de débito y crédito.

1. El primer Plan Trienal de Acción sobre la Política de los Consumidores en la Comunidad Europea (1990-1992) tuvo como consecuencia la promulgación de la Directiva 90/314/CEe sobre viajes combinados; la Directiva 92/59/ CEE sobre seguridad de los productos, y la Directiva 90/88/CEE modificando la anterior sobre crédito al consumo.

2. El segundo Plan Trienal, ${ }^{20}$ para el periodo 1993-1995, tomó como objetivo principal el desarrollo del Mercado único al servicio de los consumidores.

\footnotetext{
${ }^{16}$ Este nuevo artículo 153 sustituye al antiguo artículo 129.A del Tratado.

17 Se conoce como derecho derivado comunitario europeo el que procede de las instituciones de la Unión Europea con capacidad de producción normativa.

18 En 1973 la Asamblea Parlamentaria del Consejo de Europa aprobó la resolución 543/73 por la que se aprobaba la Carta Europea de Protección de los Consumidores. El Consejo de Ministros europeo, en reunión del 14 de abril de 1975, reconoce los derechos básicos de los consumidores y las medidas específicas para su eficacia, considerando que la mejora de las condiciones de vida es una de las misiones de la Comunidad que implica la protección de la salud, de la seguridad y de los intereses económicos de los consumidores.

${ }^{19}$ En 1975 se aprobó el Programa Preliminar de la Comunidad Europea para una política de protección e información a los consumidores; en 1981, el Segundo Programa de la Comunidad Europea para una politica de protección e información a los consumidores, y en 1985 el Programa Nuevo Impulso de la política de protección e información a los consumidores en la Comunidad Europea.

20 Aprobado el 28 de julio de 1993.
} 
ÁNGEL ACEDO PENCO

En esta fase se adoptaron los siguientes instrumentos comunitarios: la Directiva 93/13/CEe sobre cláusulas abusivas, y la Directiva 94/47/CEE sobre contratos de adquisición de un derecho de uso de bienes inmuebles a tiempo compartido.

3. El tercer Plan Trienal de Acción sobre Política de los Consumidores para el periodo 1996-1998 propició un nutrido cuerpo normativo: la Directiva 97/7/CE sobre contratos celebrados a distancia; Directiva 97/55/CE sobre publicidad comparativa, modificando la anterior de 1984 sobre publicidad engañosa; Directiva 98/7/CE nuevamente de crédito al consumo, alterando la de 1987; Directiva 98/6/CE sobre indicación de precios, y la Directiva 98/27/CE sobre acciones de cesación.

4. El cuarto Plan Trienal de Acción para la Política de los Consumidores para 1999-2001 tiene en consideración la nueva estructura del mercado, así como la mundialización de la economía y del desarrollo de las nuevas tecnologías, lo que produce un gran impacto en las nuevas formas de consumir, propiciando nuevos textos normativos: la Directiva 1999/44/CE, del 25 de mayo de 1999, sobre determinados aspectos de la venta y las garantías de los bienes de consumo, y la Decisión 2000/323/ce del 4 de mayo de 2000, de la Comisión de las Comunidades Europeas, por la que se acuerda la creación de un Comité de los consumidores.

5. El quinto Plan tuvo carácter quinquenal (2002-2006), en cuyo periodo se aprobó una de las más influyentes normas comunitarias, la Directiva 2006/123/CE, del Parlamento Europeo y del Consejo, aprobada el 12 de diciembre de 2006, relativa a los servicios en el mercado interior (conocida como la directiva de los servicios, sobre todo, profesionales), fruto de la denominada "estrategia de Lisboa". ${ }^{21}$ En 2004 se aprobó el Reglamento sobre la cooperación en materia de protección de los consumidores. ${ }^{22}$

6. El último Plan de actuación (2007-2013) se adoptó mediante la Decisión 1926/2006/ce, y quizá sea el más ambicioso de todos hasta el momento, además incluye una la elevada financiación comunitaria.

Al 15 de enero de 2012, los veintisiete países miembros de pleno derecho de la Unión Europea son, por orden alfabético: Alemania, Austria, Bélgica, Bulgaria, Chipre, República Checa, Dinamarca, Eslovaquia, Eslovenia, España, Estonia, Fin-

${ }^{21}$ La "estrategia de Lisboa" se fraguó en la reunión extraordinaria del Consejo Europeo en la capital portuguesa el 23 y 24 de marzo de 2000.

${ }_{22}$ Reglamento (cE) No. 2006/2004 del Parlamento Europeo y del Consejo, del 27 de octubre de 2004, sobre la cooperación entre las autoridades nacionales encargadas de la aplicación de la legislación de protección de los consumidores. 
landia, Francia, Grecia, Hungría, Irlanda, Italia, Letonia, Lituania, Luxemburgo, Malta, Países Bajos, Polonia, Portugal, Reino Unido, Rumanía y Suecia. ${ }^{23}$

A todos ellos, en el ámbito comunitario, con el objetivo concreto de lograr un alto nivel de protección mediante el desarrollo de las políticas de defensa de los consumidores, actualmente se les reconoce el derecho a adoptar medidas que eleven la protección básica de los consumidores, establecida en las normas comunitarias, poniendo como límite únicamente el propio mercado interior y las actuaciones reguladas en las Directivas.

Es bien sabido que las Directivas tienen el carácter de mínimos, y aunque no sean de aplicación directa, sin embargo, pueden producir el efecto directo cuando no hayan sido desarrolladas por un Estado miembro dentro del plazo fijado para ello en ellas, siempre que sean claras y precisas, e invocadas por un particular frente a un Estado miembro, no entre particulares.

\section{Rasgos esenciales del derecho de consumo español y europeo}

\section{A) Un derecho multidisciplinar}

La protección de los consumidores se estudia en esta obra desde el punto de vista del derecho privado, esto es, a la vista del derecho civil y mercantil, disciplinas que acogen la mayoría de las normas que reconocen derechos subjetivos a los consumidores y usuarios.

Pero, como se adelantó, también desde las disciplinas que se integran en el derecho público se aborda aquella protección, en especial, mediante el derecho administrativo, tanto de carácter organizativo, de control e inspección, como preventivo y sancionador. Otras ramas que se refieren a la defensa del consumidor se encuentran en el derecho tributario, sin olvidar ciertos aspectos de derecho procesal, y, desde luego, también el derecho penal, habida cuenta de diversos tipos penales específicos que castigan los supuestos más graves de atentados contra los derechos del consumidor.

\section{в) Dispone de diversas fuentes normativas}

Si bien la competencia legislativa para regular, con rango de ley formal, se va aclarando poco a poco, entre el Estado y las Comunidades Autónomas, mediante

\footnotetext{
${ }^{23}$ Son países candidatos a ingresar en la UE en el futuro: Croacia, la antigua república yugoslava de Macedonia, Turquia e Islandia. Paises candidatos potenciales a incorporarse a la Unión son: Albania, Bosnia y Herzegovina, Kosovo, Montenegro y Serbia.
} 
ÁNGEL ACEDO PENCO

la titubeante doctrina del Tribunal Constitucional, lo cierto es que, además, ha de tenerse muy en cuenta que, cada vez más, las normas de protección de los consumidores son de procedencia comunitaria que luego se transponen a los países miembros. Además, en última instancia, también las entidades locales pueden dictar ordenanzas de consumo en sus respectivos territorios. En definitiva, el derecho de consumo está formado por: 1) derecho comunitario; 2) derecho estatal; 3) derecho autonómico, y 4) derecho local.

Por tanto, las fuentes del derecho de consumo están formadas por las normas, legales y reglamentarias sobre esta materia, provenientes de las siguientes instituciones públicas: a) el Parlamento y el Consejo de la Unión Europea; $b$ ) las Cortes Generales y el gobierno de la nación española; $c$ ) las asambleas legislativas y los gobiernos de las Comunidades Autónomas, y en menor medida, $d$ ) los plenos y los alcaldes de los municipios españoles.

\section{c) Carácter imperativo de sus normas}

Las normas de derecho de consumo reconocen derechos ejercitables y exigibles, por quienes ostenten la cualidad de consumidores y usuarios, pero, ciertamente, de poco o nada serviría tal reconocimiento si los titulares de los derechos pudieran renunciar a ellos si desean contratar para adquirir el bien o servicio.

Por tal motivo, las normas de derecho de consumo suelen tener carácter imperativo, lo que se traduce en la irrenunciabilidad de los derechos que son reconocidos al consumidor y al usuario, A tal fin, el artículo 10 LCu dispone que: "la renuncia previa a los derechos que esta norma reconoce a los consumidores y usuarios es nula, siendo, asimismo, nulos los actos realizados en fraude de ley de conformidad con lo previsto en el artículo 6 del Código Civil". Al respecto, el artículo 6.4 del Código Civil español vigente (cc) indica: "los actos realizados al amparo del texto de una norma que persigan un resultado prohibido por el ordenamiento jurídico, o contrario a él, se considerarán ejecutados en fraude de ley y no impedirán la debida aplicación de la norma que se hubiere tratado de eludir".

\section{D) Cualidad tuitiva de sus preceptos}

Si algo caracteriza especialmente al derecho de consumo es precisamente su finalidad protectora a una cualidad concreta de personas, los consumidores y usuarios. Este carácter tuitivo es la razón que justifica su existencia, puesto que 
ya existen normas para todos en las otras disciplinas jurídicas, aparece el derecho de consumo para otorgar una mayor protección de la que otorga el derecho tradicional. lgual ocurre, por ejemplo, con el derecho del trabajo, donde el sujeto protegido es el trabajador frente al empleador; en el derecho de consumo es el consumidor frente al empresario.

\section{E) Protección optativa, compatible y complementaria}

A diferencia de lo que sucede en la disciplina tomada como ejemplo -el derecho del trabajo-, donde los sujetos protegidos sólo tienen un cuerpo normativo (en esencia, el Estatuto de los Trabajadores y normas complementarias), que tienen carácter exclusivo y excluyente para hacer valer sus derechos, no existiendo otra vía; sin embargo, las normas de protección de los consumidores complementan al resto del ordenamiento jurídico, es decir, los afectados, que ostenten esta cualidad de consumidor, pueden acudir a las vías específicas reconocidas sólo a éstos en el derecho de consumo, pero también, si lo desean, pueden acogerse al resto de las normas comunes del ordenamiento jurídico.

Por ello puede hablarse de un carácter optativo, pues en ocasiones (quizá pocas) el consumidor puede optar por reclamar la protección de las normas comunes (derecho civil y mercantil), o bien las de derecho de consumo. De o anterior se deduce, igualmente, el carácter compatible del derecho de consumo con el resto del ordenamiento. Y también complementario, ya que, además de las normas de consumo, e incluso una vez agotada esta vía especial, puede interesar al consumidor interponer una reclamación al amparo del derecho civil y mercantil.

\section{F) Otros caracteres básicos}

Además de los expresadas más arriba, la doctrina más reciente ha destacado otros caracteres del derecho de consumo, alguno de los cuales ya se han apuntado, y se destacan los siguientes: ${ }^{24}$

a) El marcado intervencionismo de las administraciones públicas.

b) La prevalencia, en caso de conflicto, del principio pro consumatore.

c) Supone un complemento de las normas reguladoras del mercado.

d) Está impulsando la armonización del derecho contractual europeo.

${ }^{24}$ Véase Reyes López, María José. Manual de derecho privado de consumo, Editorial La Ley, Las Rozas (Madrid), 2009, pp. 33-35. 
ÁNGEL ACEDO PENCO

e) Contiene mecanismos propios de resolución de conflictos: arbitraje.

f) Fomenta las asociaciones de consumidores y usuarios.

\section{La LCu: norma esencial de derecho de consumo en España}

\section{A) Estructura formal}

El vigente Texto Refundido de la Ley General para la Defensa de los Consumidores y Usuarios y otras leyes complementarias (LCU) se aprobó mediante el Real Decreto Legislativo 1/2007, del 16 de noviembre.

\section{B) Contenido del Texto Refundido}

Contiene 165 artículos, 6 disposiciones adicionales y 3 disposiciones finales en sus 4 libros que incorporan estas materias:

1) Libro 1 sobre "disposiciones generales", desarrollado en cinco títulos:

Título I que contiene el "ámbito de aplicación y derechos básicos de los consumidores y usuarios”, que agrupa al capítulo 1 de ámbito de aplicación; el capítulo 11 de derechos básicos de los consumidores y usuarios; capítulo 111 sobre protección de la salud y seguridad, capítulo iv sobre derecho a la información, formación y educación, y capítulo $v$ sobre la protección de los legítimos intereses económicos de los consumidores y usuarios.

Título II sobre el "derecho de representación, consulta y participación y régimen jurídico de las asociaciones de consumidores y usuarios", integrado por el capítulo 1 con el régimen jurídico básico de las asociaciones de consumidores y usuarios y el capitulo 11 sobre independencia y transparencia de las asociaciones de consumidores y usuarios, el capítulo $\mathrm{ml}$ del Registro estatal de asociaciones de consumidores y usuarios y el capítulo iv sobre la representación y consulta.

Título III sobre "cooperación institucional", que contiene el capítulo 1 de la conferencia sectorial de consumo, y el capítulo $\|$ sobre la cooperación institucional en materia de formación y control de la calidad.

Título IV con la "potestad sancionadora", donde se incluye el capítulo l sobre disposiciones generales, y el capítulo 11 de infracciones y sanciones.

Título $v$ "procedimientos judiciales y extrajudiciales de protección de los consumidores y usuarios", contiene el capítulo i sobre acciones de cesación, y el capítulo 11 sobre el sistema arbitral del consumo.

2) Libro $\|$ referido a los "contratos y garantías", donde se incluyen: 
Título I de "contratos con los consumidores y usuarios", con el capítulo I de disposiciones generales, y el capítulo 1 del derecho de desistimiento.

Título II de "condiciones generales y cláusulas abusivas", capítulo I de cláusulas no negociadas individualmente, y capítulo 11 de cláusulas abusivas.

Título III de "contratos celebrados a distancia", aglutina el capítulo 1 disposiciones generales, capítulo 11 información precontractual y contratos, capítulo 111 con el derecho de desistimiento en los contratos a distancia y el capítulo iv sobre la ejecución del contrato.

Título IV de "contratos celebrados fuera de establecimientos mercantiles", incluye el capítulo 1 sobre ámbito de aplicación, y el capítulo 11 sobre la contratación en esta modalidad.

Título $v$ de "garantías y servicios posventa", contiene el capítulo 1 de disposiciones generales sobre garantía de los productos de consumo, capítulo $\|$ sobre la responsabilidad del vendedor y derechos del consumidor y usuario, capítulo 111 del ejercicio de derechos por el consumidor y usuario, y el capítulo iv que regula la garantía comercial adicional, las obligaciones de documentación y los servicios posventa.

3) Libro 111 referente a la "responsabilidad civil por bienes o servicios defectuosos":

Título I sobre "disposiciones comunes en materia de responsabilidad", que contiene el capítulo I que desarrolla las disposiciones generales en esta materia, y el capítulo $\|$ bajo el epígrafe de responsabilidad.

Título II de "disposiciones específicas en materia de responsabilidad", contiene el capítulo 1 sobre daños causados por productos, y el capítulo 11 acerca de los daños causados por otros bienes y servicios.

4) Libro iv sobre "viajes combinados", es el último de todos, y contiene:

Título I de "disposiciones generales", compuesto por el capítulo i con el ámbito de aplicación, el capítulo $\|$ sobre información precontractual y formalización del contrato, el capítulo $\mathrm{ll}$ acerca de otros derechos del consumidor y usuario, y el capítulo iv sobre la modificación del contrato.

Título II de disposiciones relativas a la resolución del contrato y responsabilidades, que incluye el capítulo i sobre la resolución del contrato o cancelación, y el capítulo 11 , acerca del incumplimiento, responsabilidad y garantías.

\section{c) Breve valoración critica}

Partiendo del mandato constitucional del desarrollo legislativo de la protección de los consumidores en España, la LCu de 2007 destaca, como se ha visto, por 
ÁNGEL ACEDO PENCO

tratarse de un texto refundido que pretende articular en un solo cuerpo legal diversas materias, en cierto modo homogéneas, para lo cual se han escogido los ingredientes de cinco leyes importantes (una general y cuatro sectoriales) en materia de protección al consumidor, y se ha elaborado un producto final con sus luces y sus sombras.

No se comprenden los motivos por los que han sido excluidos de la "refundición” materias tan propias del derecho de consumo como el crédito al consumo, los servicios financieros a distancia, ${ }^{25}$ los servicios de la información y el comercio electrónico, las ventas de bienes inmuebles a los consumidores (viviendas), y el aprovechamiento por turno compartido de inmuebles vacacionales (cuya ley reguladora prohíbe que se denomine multipropiedad, como todo el mundo la conoce), entre otros contenidos.

Respecto de la técnica de refundición usada, la doctrina ha criticado que ciertos aspectos de la nueva lcu no tienen una explicación lógica, y sí una falta de "armonía interna entre las distintas modalidades contractuales sobre las que había de practicarse la refundición, que han permanecido con el mismo nivel de disparidad que padecían antes de la refundición". Pero se añade alguna ventaja como el interesante artículo $60 \mathrm{Lcu}$, "que unifica las normas preexistentes y uniformiza la clase de información que debe darse en la contratación con consumidores". ${ }^{26}$

Se ha escrito que la valoración acerca de la calidad de la refundición es positiva, tanto en su sistemática como en buena parte de las modificaciones introducidas. No se detectan, además, omisiones relevantes ni "efectos secundarios" imprevistos. En definitiva, para esta doctrina que se glosa, la nueva tcu "mejora la situación legislativa anterior (la derogada Ley del Consumidor 1984 y las demás leyes especiales que ahora se refunden)". ${ }^{27}$

Respecto de la valoración del estado del desarrollo legislativo actual del precepto constitucional de protección de los consumidores y usuarios, contenido, como se ha visto, en el artículo $51 \mathrm{cE}$, la nueva regulación española resulta abiertamente positiva, por cuanto, a la vista de la doctrina del Tribunal Constitucional español sobre esta materia, se ha logrado, también ahora en vía legislativa, un

25 Fernández Pérez. El nuevo régimen de la contratación a distancia con consumidores: especial referencia a servicios financieros, editorial La Ley, Madrid, 2009.

${ }^{26}$ Carrasco Perera, Ángel. "Texto Refundido de la Ley General para la Defensa de los Consumidores y Usuarios (Real Decreto Legislativo 1/2007). Ámbito de aplicación y alcance de la refundición", en Aranzadi Civil, No. 1, 2008, pp. 2215-2225.

${ }_{27}$ Cavanillas MúgicA, S. "El Real Decreto Legislativo 1/2007 por el que se aprueba el Texto Refundido de la Ley General para la Defensa de los Consumidores y Usuarios y otras leyes complementarias", en Aranzadi Civil, No. 1, 2008, pp. 2133-2166. 
mayor respeto de los principios y postulados constitucionales que de aquel precepto se derivan.

Finalmente, la adecuación de la legislación de protección a los consumidores a los preceptos constitucionales continúa siendo perfilada por el Tribunal Constitucional español, en especial respecto de los conflictos competenciales entre el Estado y las Comunidades Autónomas, con la posibilidad de servir como referente más cercano en el tiempo la reciente STc 26/2012, del 1 de marzo de 2012. ${ }^{28}$

En definitiva, no sólo la doctrina del Tribunal Constitucional viene delimitando los perfiles del nuevo derecho de consumo en España, sino también, y en mayor medida tal vez, el nutrido cuerpo normativo que procede de los tratados y de las instituciones de la Unión Europea que, a pasos de gigante, van homogenizando un nuevo cuerpo legislativo con normas de derecho privado que persiguen un elevado nivel de protección jurídica, de aplicación casi idéntica en los veintisiete de países que la conforman, cuya función es elevar la calidad de vida de los ciudadanos comunitarios, esto es, de los consumidores.

Y es que, en puridad, en los últimos tiempos, pocas parcelas del derecho privado, como ha ocurrido con el derecho de consumo, se han visto tan influidas por las normas constitucionales, tal vez debido tanto a la gran proyección sobre los derechos civiles de los ciudadanos, como al enorme éxito del desarrollo de esta joven y apasionante disciplina.

\footnotetext{
28 Sentencia del Pleno del Tribunal Constitucional 26/2012, del 1 de marzo de 2012 (BOE No. 75, del 28 de marzo de 2012, en cuyo fundamento de derecho 3 se afirma sobre esta materia que las Comunidades Autónomas españolas: "han de respetar las competencias del Estado relacionadas en el artículo 149.1 CE, en especial aquéllas explícitamente mencionadas por el texto estatutario en relación con las competencias autonómicas en materia de defensa de los consumidores y usuarios y de comercio interior pues sólo entonces será dable reconocer que la autonómica se ha actualizado en el respeto a su marco delimitador propio, constitucional y estatutario, cuestión ésta que deberemos determinar en relación a cada uno de los preceptos objeto del presente proceso al examinar su relación con las competencias estatales que se entienden vulneradas como son, especialmente, las derivadas del artículo 149.1.6 y 13 CE".
} 